\title{
Metachronous Gastric Cancer: Another Hurdle for Successful Endoscopic Treatment for Early Gastric Cancer?
}

\author{
Moon Won Lee and Gwang Ha Kim \\ Department of Internal Medicine, Pusan National University School of Medicine and Biomedical Research Institute, Pusan National University \\ Hospital, Busan, Korea
}

See "Clinical Outcomes of Metachronous Gastric Cancer after Endoscopic Resection for Early Gastric Cancer" by Jue Lie Kim, et al. on page 190, Vol. 14, No. 2, 2020

Endoscopic submucosal dissection (ESD) has been widely used as a curative treatment for early gastric cancers (EGCs). ESD has historically high en bloc and curative resection rates for EGCs, regardless of their size and location. ESD is a minimal invasive procedure compared to surgical gastrectomy, and is an advantageous approach due to preservation of the entire stomach. Despite these advantages, there is a concerning rate of newly developed gastric cancers in the preserved stomach after ESD. Metachronous gastric cancer (MGC) is defined as a newly developed gastric cancer occurring at a previously uninvolved site 1 year or more after index ESD.

In this issue of Gut and Liver, Kim et al. ${ }^{1}$ evaluated the clinical outcomes of MGC after ESD for EGCs between the re-ESD and surgery groups. During the mean follow-up period of 66 months, MGC occurred in 117 of 1,302 patients (9\%) who had undergone ESD for EGCs; of patients with MGC, 90 underwent re-ESD and 22 underwent surgery. In multivariate analysis, a low body mass index, multiplicity of index cancers, diffuse or mixed-type Lauren classification, submucosal or deeper invasion, and upper stomach location were factors associated with surgery for MGC. Interestingly, the surgical group showed a significantly shorter overall survival rate than the re-ESD group.

Risk factors associated with development of MGC include male sex, old age, current smoking, severe atrophy, intestinal metaplasia, persistent Helicobacter pylori infection, pepsinogen (PG) I/II ratio $\leq 3$, differentiated-type histology, and multiple initial gastric cancers. ${ }^{2-9}$ Male sex, old age, and current smoking are also potential risk factors for gastric cancer in the gen- eral population. According to Correa's hypothesis, intestinaltype gastric cancer may develop as chronic $H$. pylori infection evolves over time to chronic gastritis, atrophy, intestinal metaplasia and dysplasia. Because ESD is an organ-sparing treatment, gastric mucosa with histologic changes remains after ESD for EGCs. Therefore, risk factors for MGC are like to those for intestinal-type gastric cancer. Some studies suggest that $H$. pylori eradication may not always reduce the development of MGC after ESD, especially in cases of multiple initial gastric cancers; ${ }^{9}$ severe atrophy with intestinal metaplasia represents the "point of no return" at which the development of gastric cancer can no longer be prevented by $H$. pylori eradication alone. On the contrary, many studies suggest that persistent $H$. pylori infection is a risk factor for MGC, and a recent meta-analysis shows that $H$. pylori eradication can effectively reduce rates of MGC. ${ }^{10}$ Therefore, $H$. pylori eradication is strongly recommended for prevention of MGC after ESD for EGCs. Serum PG I/II ratio can also be used as a predictive indicator of the development of MGC after $\mathrm{ESD}$, as it is a reliable marker in the diagnosis of more extensive atrophy. $^{8}$

Because gastric atrophy progresses from the antrum to the lower body, MGC is usually located at the lower third of the stomach and appears as a small, differentiated-type intramucosal cancer $<20 \mathrm{~mm}$ in size. ${ }^{6,11}$ Most patients with MGC already have marked atrophy and intestinal metaplasia in the background gastric mucosa. Because $H$. pylori eradication decreases inflammation caused by $H$. pylori infection, it can become even more difficult to detect early MGC and its margins. Therefore,

Correspondence to: Gwang Ha Kim

Department of Internal Medicine, Pusan National University School of Medicine and Biomedical Research Institute, Pusan National University Hospital, 179 Gudeok-ro, Seo-gu, Busan 49241, Korea

Tel: +82-51-240-7869, Fax: +82-51-244-8180, E-mail: doc0224@pusan.ac.kr pISSN 1976-2283 eISSN 2005-1212 https://doi.org/10.5009/gnl20018

(c) This is an Open Access article distributed under the terms of the Creative Commons Attribution Non-Commercial License (http://creativecommons.org/licenses/by-nc/4.0) which permits unrestricted non-commercial use, distribution, and reproduction in any medium, provided the original work is properly cited. 
Table 1. Incidence and Risk Factors of Metachronous Gastric Cancers Occurring after Endoscopic Resection for Early Gastric Cancers

\begin{tabular}{|c|c|c|c|c|}
\hline Study (year) & Subject no. & $\begin{array}{l}\text { Mean follow-up } \\
\text { period (yr) }\end{array}$ & $\begin{array}{l}\text { Incidence of metachronous } \\
\text { cancer }(\%)\end{array}$ & Risk factors \\
\hline \multirow[t]{2}{*}{ Abe et al. $(2015)^{2}$} & 1,526 & 6.8 & 15.6 & Multiple initial cancers \\
\hline & & & & Male sex \\
\hline \multirow[t]{2}{*}{ Sugimoto et al. $(2015)^{3}$} & 155 & 4.2 & 14.8 & Intestinal metaplasia \\
\hline & & & & Neutrophil infiltration \\
\hline \multirow[t]{3}{*}{ Mori et al. (2016) ${ }^{4}$} & 594 & 4.5 & 13.3 & Male sex \\
\hline & & & & Severe atrophy \\
\hline & & & & Multiple initial cancers \\
\hline \multirow[t]{2}{*}{ Ami et al. $(2017)^{5}$} & 539 & 8.7 & 13.0 & Old age (>60 yr) \\
\hline & & & & Current smoking \\
\hline Cho et al. $(2017)^{6}$ & 2,334 & 3.5 & 3.3 & Aging \\
\hline \multirow[t]{2}{*}{ Chung et al. (2017) ${ }^{7}$} & 185 & 5.6 & 13.0 & Old age (>70 yr) \\
\hline & & & & Persistent Helicobacter pylori infection \\
\hline \multirow[t]{2}{*}{ Kwon et al. (2017) $)^{8}$} & 590 & 4.0 & 10.8 & Persistent $H$. pylori infection \\
\hline & & & & Serum pepsinogen I/II ratio $\leq 3$ \\
\hline \multirow[t]{3}{*}{ Okada et al. (2019) ${ }^{9}$} & 384 & 4.1 & 15.6 & Aging \\
\hline & & & & Differentiated-type histology \\
\hline & & & & Multiple initial cancers \\
\hline
\end{tabular}

more time and biopsies of suspicious lesions are needed during surveillance endoscopy to identify MGC.

The incidence of MGC following ESD for EGCs has been reported to be $3.3 \%$ to $15.6 \%$, according to the follow-up duration (Table 1). The mean annual incidence of MGC after ESD is approximately $2.5 \%$ to $3.5 \%$ and linearly increases; ${ }^{11}$ a 10 -year cumulative incidence of MGC may increase up to $22.7 \%{ }^{2}$ Thus, clinicians should perform annual surveillance endoscopy for at least 10 years after ESD, paying special attention to the lower third of the stomach.

MGC can be treated similarly to an initial EGC. Because MGC is usually a small, differentiated-type, mucosal cancer, it can be treated by ESD. Long-term treatment outcomes of ESD for MGC are excellent when curative resection is achieved. Previous studies have reported that curative resection rates for MGC are 89\% to $99 \%$, and the 5-year and 10-year disease-specific survival rates in patients with MGC after curative ESD are 99\% and 93\%, respectively. ${ }^{2,4,6}$ Surgical treatment is necessary for MGC with beyond the extended criteria of ESD for EGCs.

In summary, patients who have undergone ESD for EGCs experiences a high incidence of MGC that increases linearly for at least 10 years. Although $H$. pylori eradication can decrease the incidence of MGC, it does not completely reduce the risk for MGC. Surveillance endoscopy should be used to identify MGC; risk stratification and tailored follow-up intervals should be developed according to the patient's risk factors for MGC. Currently, a minimum of annual surveillance endoscopy is recommended for detecting MGC after ESD for EGCs.

\section{CONFLICTS OF INTEREST}

No potential conflict of interest relevant to this article was reported.

\section{ORCID}

Moon Won Lee

https://orcid.org/0000-0002-8411-6398

Gwang Ha Kim

https://orcid.org/0000-0001-9721-5734

\section{REFERENCES}

1. Kim JL, Kim SG, Kim J, et al. Clinical outcomes of metachronous gastric cancer after endoscopic resection for early gastric cancer. Gut Liver 2020;14:190-198.

2. Abe S, Oda I, Suzuki H, et al. Long-term surveillance and treatment outcomes of metachronous gastric cancer occurring after curative endoscopic submucosal dissection. Endoscopy 2015;47:1113-1118.

3. Sugimoto T, Yamaji Y, Sakitani K, et al. Neutrophil infiltration and the distribution of intestinal metaplasia is associated with metachronous gastric cancer following endoscopic submucosal dissection. Can J Gastroenterol Hepatol 2015;29:321-325.

4. Mori G, Nakajima T, Asada K, et al. Incidence of and risk factors for metachronous gastric cancer after endoscopic resection and successful Helicobacter pylori eradication: results of a large-scale, multicenter cohort study in Japan. Gastric Cancer 2016;19:911918.

5. Ami R, Hatta W, Iijima K, et al. Factors associated with metachro- 
nous gastric cancer development after endoscopic submucosal dissection for early gastric cancer. J Clin Gastroenterol 2017;51:494499.

6. Cho CJ, Ahn JY, Jung HY, et al. The incidence and locational predilection of metachronous tumors after endoscopic resection of high-grade dysplasia and early gastric cancer. Surg Endosc 2017;31:389-397.

7. Chung CS, Woo HS, Chung JW, et al. Risk factors for metachronous recurrence after endoscopic submucosal dissection of early gastric cancer. J Korean Med Sci 2017;32:421-426.

8. Kwon Y, Jeon S, Nam S, Shin I. Helicobacter pylori infection and serum level of pepsinogen are associated with the risk of meta- chronous gastric neoplasm after endoscopic resection. Aliment Pharmacol Ther 2017;46:758-767.

9. Okada K, Suzuki S, Naito S, et al. Incidence of metachronous gastric cancer in patients whose primary gastric neoplasms were discovered after Helicobacter pylori eradication. Gastrointest Endosc 2019;89:1152-1159.

10. Fan F, Wang Z, Li B, Zhang H. Effects of eradicating Helicobacter pylori on metachronous gastric cancer prevention: a systematic review and meta-analysis. J Eval Clin Pract 2020;26:308-315.

11. Abe S, Oda I, Minagawa T, et al. Metachronous gastric cancer following curative endoscopic resection of early gastric cancer. Clin Endosc 2018;51:253-259. 